\title{
PENGGUNAAN APLIKASI COREL DRAW DAN ADOBE PHOTOSHOP UNTUK DIGITAL WATERMARKING ARSIP CITRA DIGITAL
}

\author{
Herman Setyawan, S.Pd. ${ }^{\prime}$
}

\begin{abstract}
Abstrak
Arsip merupakan aset yang tak ternilai harganya. Sewaktu berfungsi sebagai arsip dinamis, arsip cenderung tertutup untuk diakses secara umum. Ketika arsip dinyatakan sebagai arsip statis, arsip tersebut cenderung bersifat terbuka. Keterbukaan secara luas bagi masyarakat untuk mengakses arsip mengakibatkan maraknya akses arsip di lembaga-lembaga kearsipan. Hal ini menyebabkan khasanah arsip statis menjadi rentan terhadap kerusakan.

Dalam rangka melindungi arsip dari kerusakan akibat banyaknya tangan yang menyentuh fisik arsip, lembaga kearsipan dapat menyajikan khasanah arsipnya berupa arsip digital. Arsip digital rentan terhadap penyalahgunaan, sebab sangat mudah disalin dan dimanipulasi. Oleh karena itu, untuk menjaga keutuhan dan keaslian informasinya, dapat diterapkan digital watermark pada arsip digital. Pemberian digital watermark dapat dilakukan dengan berbagai aplikasi. Adobe Photoshop dan Corel Draw adalah contoh aplikasi yang mudah digunakan untuk memberikan digital watermark pada arsip.
\end{abstract}

kata kunci: arsip citra digital, digital watermark, Adobe Photoshop, Corel Draw

\section{A. Pendahuluan}

Berbagai pihak menyatakan bahwa arsip itu penting, setidaknya bagi masyarakat yang telah memanfaatkan arsip untuk mendapatkan informasi dalam berbagai keperluan. Kesadaran masyarakat tentang arti penting arsip juga berangsur meningkat. Masalah-masalah yang terjadi akibat kehilangan arsip membuat menyadarkan bahwa arsip itu penting. Banyak hal buruk terjadi disebabkan oleh hilang atau

Arsiparis Arsip UGM 
rusaknya arsip. Oleh karena itu, banyak pihak mulai memberi perhatian lebih pada pengelolaan arsipnya. Untuk mengakomodasi perhatian tersebut, pemerintah melalui Arsip Nasional Republik Indonesia (ANRI), lembaga kearsipan daerah, dan lembaga kearsipan perguruan tinggi mengadakan sosialisasi secara gencar. Sosialisasi tersebut tidak hanya mengenai arti penting arsip, namun juga tata kelola, sarana penyimpanan, masa simpan arsip, metode preservasi, dan akses arsip.

Dalam hal akses arsip, lembaga kearsipan memberikan kesempatan yang luas kepada masyarakat untuk mengakses arsip. Arsip cenderung terbuka untuk umum, kecuali beberapa arsip yang mengandung unsurunsur rahasia, atau bahkan sangat rahasia, seperti kasus hukum dan hal-hal yang membahayakan negara. Beberapa arsip juga dinyatakan terbatas, yaitu hanya boleh diakses oleh pihak tertentu berdasar peraturan. Dalam
Peraturan Kepala ANRI Nomor 18 Tahun 2011 tentang Tata Cara Pembuatan Daftar, Pemberkasan dan Pelaporan, serta Penyerahan Arsip Terjaga, tersirat bahwa klasifikasi keamanan arsip dibedakan dalam tiga kategori, yaitu: sangat rahasia, rahasia, dan terbatas. Namun, pada umumnya secara mayoritas arsip bersifat terbuka kecuali atas pertimbangan tertentu.

Keterbukaan akses arsip tersebut mengundang masyarakat un t u k berama i-ramai memanfaatkan arsip untuk berbagai keperluan, seperti penelitan, penulisan buku, pameran, atau bahkan sekedar bernostalgia. Dengan ramainya akses arsip, lembaga kearsipan merasa senang karena dapat menyajikan produknya secara maksimal. Terjadi perubahan paradigma bahwa arsip statis bukan lagi menjadi arsip yang "tertidur" sampai akhir zaman, namun mulai dibangunkan untuk "menemani hidup" masyarakat 
dalam kehidupan berbangsa dan bernegara. Akan tetapi, banyak pihak pengelola arsip mulai khawatir, karena semakin sering arsip diakses, semakin rentan pula arsip tersebut mengalami kerusakan. Apalagi arsip yang paling digemari oleh pengguna pada umumnya adalah arsip yang sudah tua. Semakin tua usia arsip, semakin menarik bagi sebagian besar pengguna.

\section{B. Kerangka Pemikiran}

Dalam Peraturan Kepala ANRI Nomor 30 Tahun 2011 tentang Pedoman Penggunaan Kertas untuk Arsip/Dokumen Permanen disebutkan bahwa untuk pelestarian arsip, langkah yang dapat dilakukan adalah dengan upaya proaktif, yakni penyelamatan dan pelestarian arsip/dokumen pada tahap penciptaan yang dilakukan oleh pencipta arsip sebagai objek hulu penyelenggaraan kearsipan. Upaya tersebut berupa penggunaan kertas sebagai media rekam informasi arsip/dokumen permanen yang memiliki kualitas baik sesuai dengan standar internasional. Dalam Peraturan Kepala ANRI Nomor 2 Tahun 2014 tentang Pedoman Tata Naskah Dinas disebutkan istilah kertas permanen, yaitu kertas yang bebas asam (acid free) atau memiliki tingkat keasaman rendah, memiliki keawetan dan daya tahan tinggi dalam jangka waktu lama. Kertas jenis ini digunakan sebagai bahan untuk mencipta naskah dinas yang bernilaiguna sekunder atau permanen.

Arsip yang terlanjur tercipta menggunakan kertas kualitas rendah, lembaga kearsipan dapat menyajikan arsip secara digital. Bagi arsip yang diciptakan secara digital, hal ini tidak menjadi masalah. Akan tetapi, bagi arsip yang berupa berkas konvensional, arsip harus terlebih dahulu dialihmediakan menjadi citra digital. Penyajian arsip citra digital memungkinkan arsip asli tetap terjaga dengan baik karena tidak 
disentuh oleh pengguna. Ada kalanya terjadi penyalahgunaan arsip citra digital, sebab format digital sangatlah mudah disalin/dicopy dan disebarluaskan. Oleh karena itu, arsip citra digital sudah selayaknya dilindungi sedemikan rupa agar sumber, pencipta, atau hak kepemilikan arsip tetap tercantum pada wajah citra digital. Dalam proteksi semacam ini, dapat digunakan digital watermark, yaitu tulisan atau gambar yang menempel pada citra digital untuk keperluan pengamanan fisik dan informasi arsip. Pemberian digital watermark dapat diterapkan pada semua jenis format digital, namun pada kesempatan ini penulis hanya akan membahas digital watermark pada arsip berbasis gambar.

Peraturan Kepala ANRI Nomor 28 Tahun 2014 tentang Penggunaan Digital Watermark pada Hasil Digitalisasi Arsip Vereenigde Oostindische Compagnie di Lingkungan Arsip Nasional Republik Indonesia menyebutkan bahwa arsip citra digital merupakan arsip hasil penangkapan atau alih media suatu objek fisik menggunakan alat pencitraan digital. Proses alih media dari konvensional ke format digital disebut sebagai digitalisasi. Digitalisasi adalah tindakan dan prosedur yang dilalui dalam proses alih media dengan mengubah bentuk dari format tercetak menjadi format digital.

Arsip dalam bentuk digital terdiri dari berbagai format. Dalam buku Panduan Umum Digitalisasi Arsip di Lingkungan Universitas Gadjah Mada disebutkan bahwa arsip format digital meliputi arsip berbasis tekstual (dalam format $. d o c, . x l s$, .ppt dan .pdf), berbasis gambar (dalam format .jpeg, . $b m p$, .tiff..gif, dan .png), berbasis audio (format mp3, WAV, $A A C$, WMA, OggVorbis, Real Audio, dan MIDI), dan berbasis video (format $A V I$, $M P E G$, Real Video, MOV, dan $3 G P)$.

Seperti telah disampaikan bahwa dalam rangka pengamanan 
fisik dan informasi arsip, dapat diterapkan digital watermark. Peraturan Kepala ANRI Nomor 28 Tahun 2014 juga menyebutkan bahwa Digital watermark adalah tanda berupa gambar dan/atau tulisan tembus pandang pada hasil digitalisasi yang dibuat bersamaan saat diproduksi sebagai bagian dari fungsi pengamanan fisik dan informasi arsip.

Tujuan utama pemberian digital watermark adalah untuk memberikan tanda pada arsip. Untuk memberikan digital watermark untuk keseluruhan khazanah arsip dapat digunakan aplikasi Image Magick, JACo Watermark, dan aplikasi serupa lainnya. Jika digital watermark yang diinginkan berbeda antara satu arsip dengan arsip lainnya, dapat pula digunakan aplikasi Adobe Photoshop dan Corel Draw. Dalam Wikipedia Bahasa Indonesia disebutkan bahwa Adobe Photoshop atau biasa disebut Photoshop, adalah perangkat lunak editor citra buatan
Adobe Systems yang dikhususkan untuk pengeditan foto/gambar bitmap dan pembuatan efek. Bitmap adalah istilah untuk menggambarkan representasi dari citra grafis yang terdiri dari susunan titik yang tersimpan di memori komputer. Sedangkan Corel Draw adalah editor grafik vektor yang dikembangkan oleh sebuah perusahaan di Kanada bernama Corel. Grafik vektor merupakan gambar digital yang berbasiskan persamaan matematis. Gambar Vektor terdiri dari penggabungan koordinat koordinat titik menjadi garis atau kurva untuk kemudian menjadi sebuah objek, sehingga gambar tidak menjadi pecah walaupun diperbesar atau diperkecil.

\section{Pembahasan}

Sebelum membahas tata cara membuat digital watermark, terlebih dahulu perlu dipastikan bahwa dalam penggandaan arsip foto, sering digunakan ukuran atau dimensi foto yang akan dicetak. 
Oleh karena itu, sebaiknya editor gambar menentukan terlebih dahulu mengenai ukuran yang diinginkan. Berikut ukuran yang umum digunakan dalam mencetak gambar/foto:

\begin{tabular}{|c|c|c|}
\hline KODE & Dalam CM & Dalam Inchi \\
\hline $2 \mathrm{R}$ & $6,35 \times 8,89$ & $2,5 \times 3,5$ \\
\hline $3 \mathrm{R}$ & $8,89 \times 12,7$ & $3,5 \times 5$ \\
\hline $4 \mathrm{R}$ & $10,6 \times 15,24$ & $4 \times 6$ \\
\hline $5 \mathrm{R}$ & $1,7 \times 17,78$ & $5 \times 7$ \\
\hline $6 \mathrm{R}$ & $15,24 \times 20,32$ & $6 \times 8$ \\
\hline $8 \mathrm{R}$ & $20,32 \times 25,40$ & $8 \times 10$ \\
\hline $10 \mathrm{R}$ & $25,40 \times 30,5$ & $10 \times 12$ \\
\hline $10 \mathrm{R} \mathrm{Plus}$ & $25,40 \times 38,1$ & $9,9 \times 14,85$ \\
\hline $12 \mathrm{R}$ & $30,48 \times 39,37$ & $12 \times 15,5$ \\
\hline $16 \mathrm{R}$ & $40,64 \times 50,8$ & $16 \times 20$ \\
\hline $20 \mathrm{R}$ & $50,8 \times 60,96$ & $20 \times 24$ \\
\hline $24 \mathrm{R}$ & $60,96 \times 80,01$ & $24 \times 31,5$ \\
\hline $60 \mathrm{R}$ & $75 \times 100$ & $30 \times 40$ \\
\hline
\end{tabular}

1. Pemberian Digital Watermark dengan Aplikasi Corel Draw Aplikasi Corel Draw mengalami perkembangan versi dari masa ke masa. Pada kesempatan ini, penulis menggunakan Corel Draw versi $\mathrm{X} 7$.

a. Membuka aplikasi
Untuk membuka aplikasi, bukalah dari program, lalu pilihlah ukuran kertas yang akan digunakan sesuai ukuran cetak. Aplikasi yang telah tebuka akan menampilkan halaman kerja dengan menu tools terletak di sebelah kiri dan pengaturan menu tools berada di atas. 


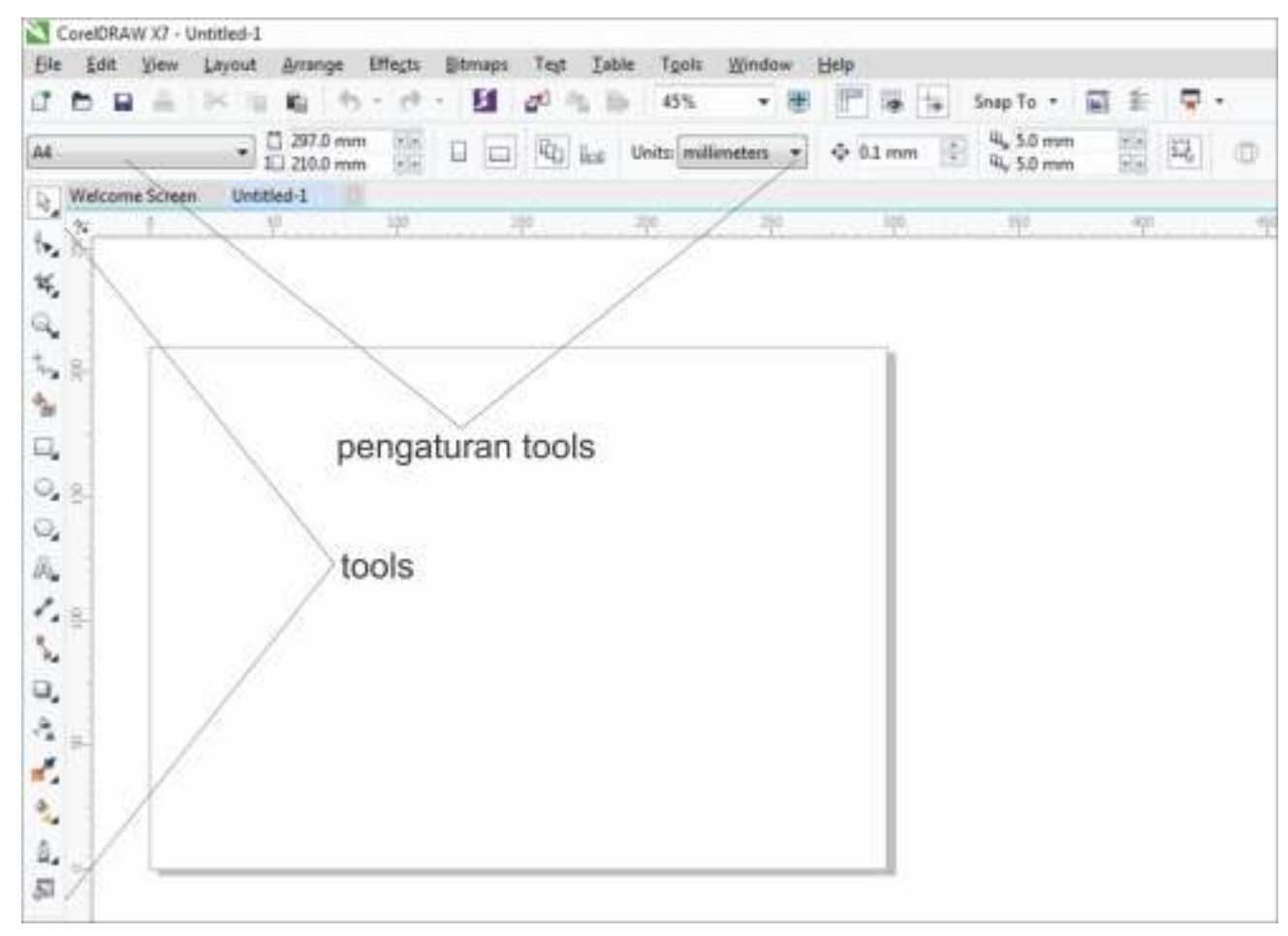

Gambar 1. Tampilan kerja Corel Draw

b. Membuat bidang cetak

\section{Gunakan rectangle}

tools untuk membuat sebuah kotak, lalu aturlah ukurannya seperti ukuran rasio cetak yang diinginkan. Kotak yang telah dibuat kemudian diklik, dan tekan "P" agar kotak berada di tengah kertas/page.

c. Memasukkan gambar target
Gambar yang akan diberi digital watermark disebut gambar target. Gambar target dapat dimasukkan melalui menu file > import. Gambar target yang telah diimpor kemudian diklik dan tekan "P" untuk membuatnya ditengah kertas/page. 


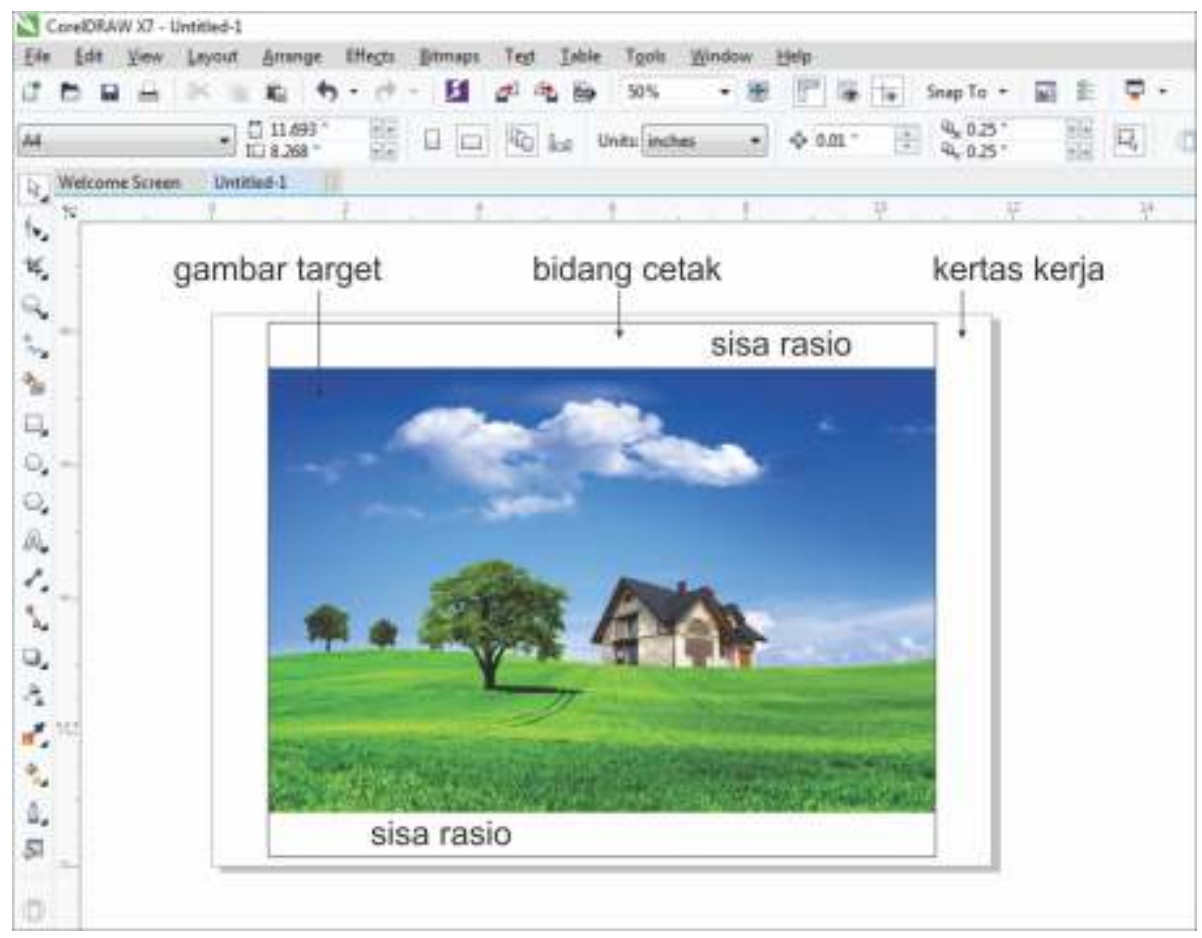

Sumber: http://www.planwallpaper.com/static/images/hd_nature_wallpaper.jpg Gambar 2: memasukkan gambar target dan bidang cetak

Sesuaikan ukuran gambar target agar memenuhi bidang cetak dengan tidak melebihi (keluar) dari bidang cetak. Adakalanya rasio ukuran gambar target dan rasio bidang cetak tidaklah seimbang, sehingga terdapat area putih yang merupakan sisa rasio

\section{d. Membuat digital watermark}

Untuk membuat digital watermark berupa logo, impor logo dari database komputer, dan tempatkan logo di tempat yang diinginkan. Demikian pula untuk membuat digital watermark berupa tulisan (teks), gunakan text tools. Atur dan sesuaikan warna, jenis tulisan dan ukuran tulisan. Untuk mengatur transparansi logo, gunakan transparency tools, lalu atur atau pilih pengaturan 
transparency sesuai

$\mathrm{k}$ e i n g i n a n. P a d a

kesempatan ini penulis

memilih pengaturan

transparency> substract.
Untuk mengatur transparansi teks, gunakan transparency tools, lalu gunakan menu transparency >overlay.

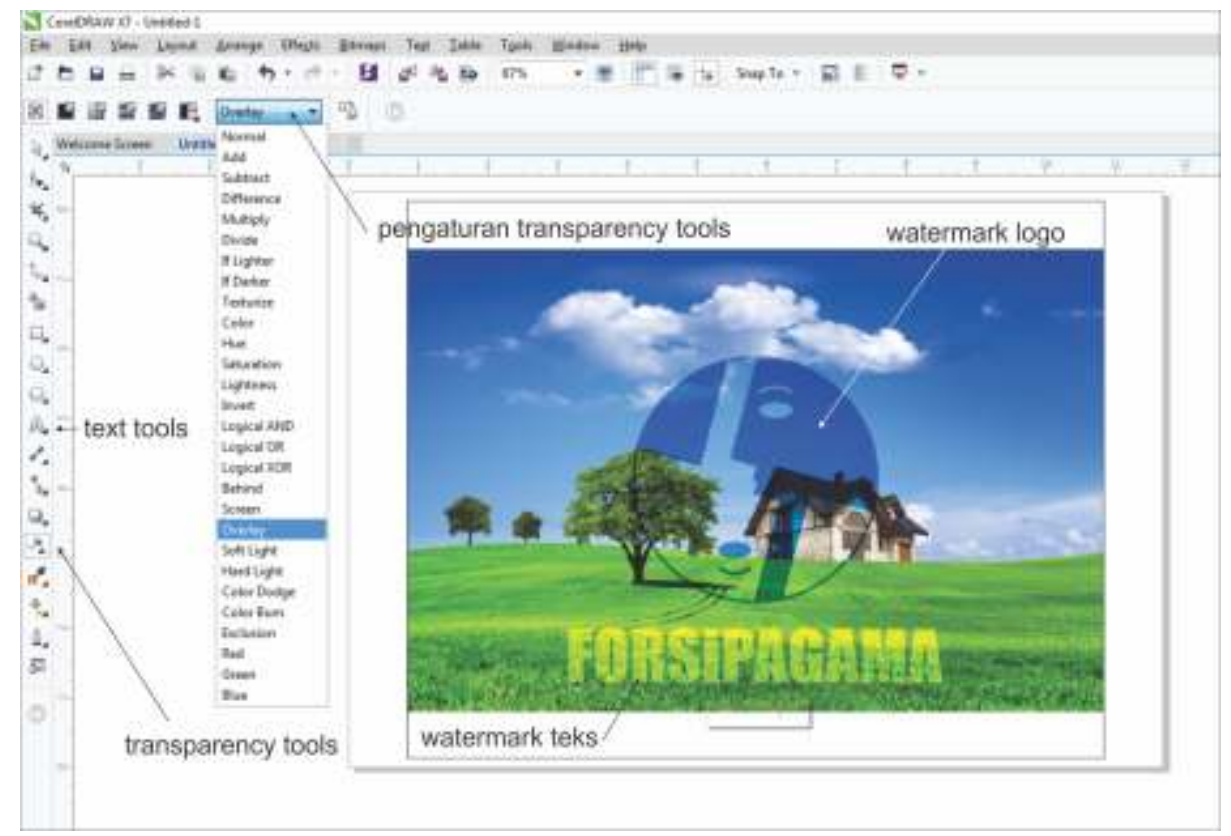

Gambar logo: Logo Forum Komunikasi Kearsipan Universitas Gadjah Mada (Forsipagama)

Gambar 3: penerapan watermark logo dan teks

e. Menyimpan gambar

Untuk menyimpan

gambar yang telah diberi

digital watermark, gunakan menu file $>$ export untuk mendapatkan gambar .jpeg, .gif, .png, dan lainlain, sedangkan untuk mendapatkan berkas .pdf gunakan menu publish. 
2. Pemberian Digital Watermark dengan Aplikasi Adobe Photoshop

$$
\text { Adobe Photoshopjuga }
$$
mengalami perkembangan dalam beberapa versi. Pada kesempatan ini, penulis ingin menyampaikan pemberian digital watermark dengan Adobe Photoshopversi CC 2015. Digital watermark yang akan dibahas adalah berupa tulisan tembus pandang dengan logo.

a. Membuka aplikasi

Untuk membuka aplikasi, bukalah aplikasi pada program, lalu pilih new untuk membuat gambar baru atau open (untuk membuka gambar dari database komputer).Jika memilih new, maka akan tampil jendela baru, sedangkan jika memilih open, akan muncul jendela explorer untuk memilih gambar yang akan diedit, lalu pilihlah gambar yang dikehendaki.

b. $\mathrm{M} \mathrm{e} \mathrm{m} \mathrm{b} \mathrm{u} \mathrm{k} \mathrm{a} \mathrm{d} \mathrm{a} \mathrm{n}$ menyesuaikan ukuran gambar

Buka gambar yang dikehendaki. Gambar yang dikehendaki selanjutnya disebut target. Target tersebut kemudian di sesuaikan ukurannya dengan memilih crop tool (c). Pilih salah satu ukuran cetak di atas, misalnya $8 \mathrm{R}=8 \times 10$ inchi. Untuk mendapatkan rasio landscape, maka ukuran 8 x 10 dibalik menjadi $10 \times 8$ pada menu ratio.

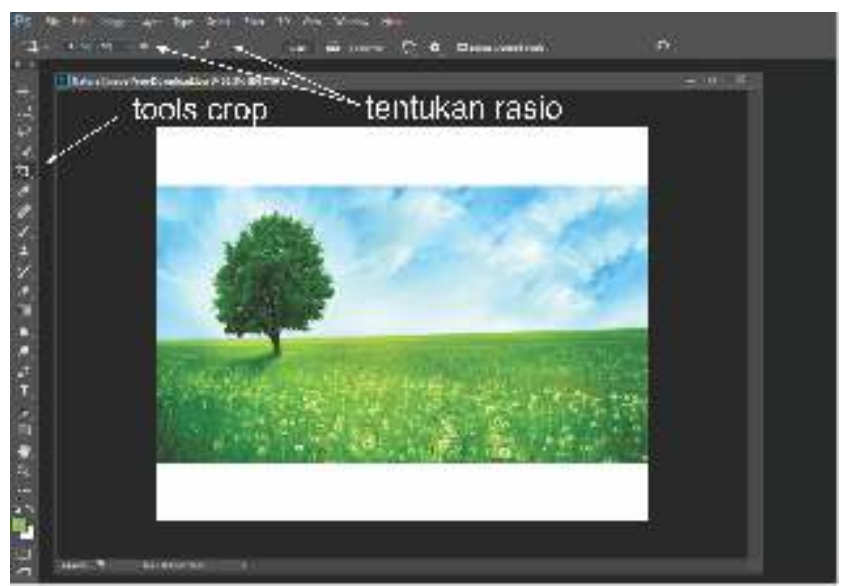

sumber: http://www.pixelstalk.net/

Gambar 4: menyesuaikan gambar 
Tidak semua target memiliki ukuran yang sesuai dengan rasio ukuran cetak. Dalam menyesuaikan ukuran, menu crop tool biasanya akan memotong gambar, sehingga gambar tidak ditampilkan secara penuh. Oleh karena itu, garis batas crop harus diperbesar sehingga semua gambar akan masuk ke dalam bingkai crop dan muncul area putih untuk memenuhi ukuran cetak.

c. Menerapkan logo diinginkan melalui menu open. Klik dan draglogo ke target, sehingga logo dan target menjadi satu. Untuk $\mathrm{m}$ e $\mathrm{n} \mathrm{g}$ h i 1 a $\mathrm{ng} \mathrm{k} \mathrm{a} \mathrm{n}$ background logo, gunakan magic wand tool (pada deretan tools sebelah kiri), klik lalu delete bagian yang a $\mathrm{k}$ a $\mathrm{n}$ d i h a $\mathrm{p} \mathrm{u} \mathrm{s}$ (background). Nama tools untuk setiap versi dari Adobe Photoshop mungkin sedikitberbeda.

B uka logo yang

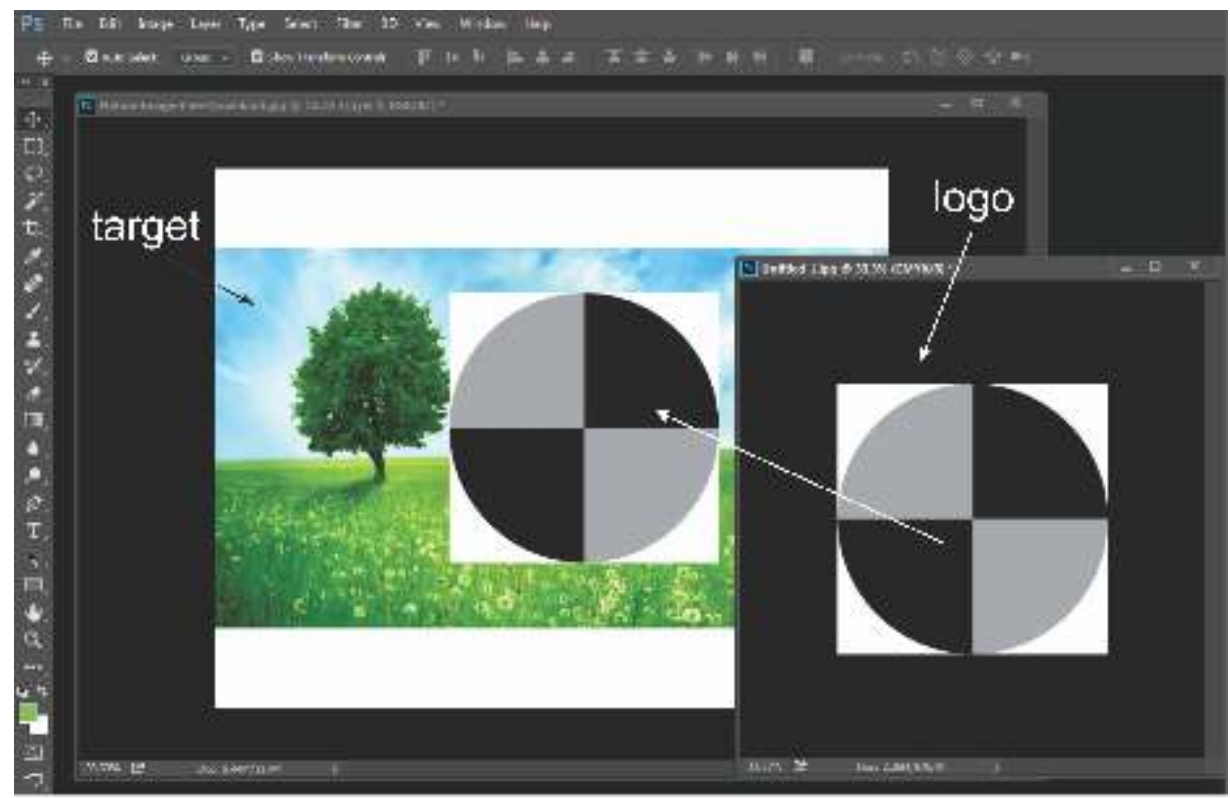

Gambar 5: penerapan logo 
d. membuat logo transparan

Untuk membuat logo

menjadi trasparan, klik layer logo, kemudian turunkan

opacity dan fill layer tersebut sesuai kebutuhan.

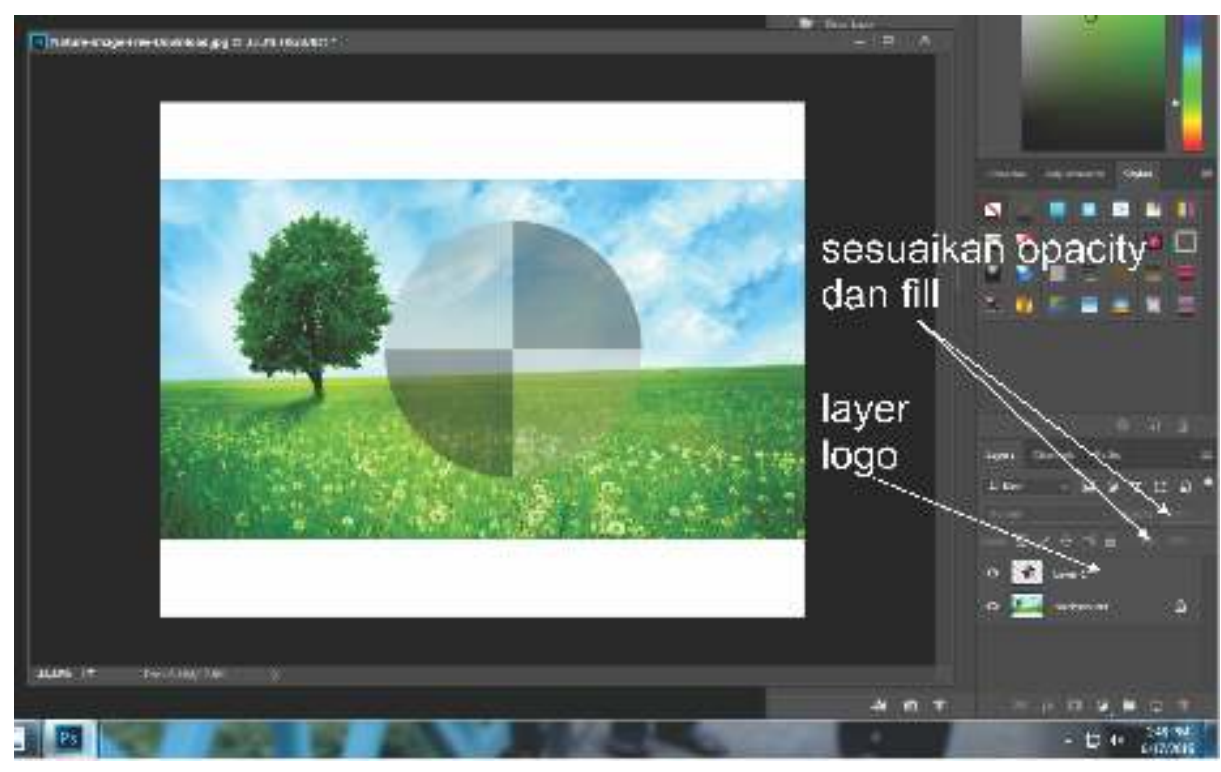

Gambar 6: pengaturan transparansi

e. menerapkan watermark teks (tulisan)

$\mathrm{Unt} \mathrm{u} \mathrm{k} \mathrm{me} \mathrm{m} \mathrm{buat}$ watermark berupa tulisan, gunakan Horizontal Type

Tool. Seperti contoh di atas, watermark berupa tulisan "contoh". Watermark kemudian diatur jenis tulisan dan ukurannya serta warnanya. Untuk membuat menjadi transparan, atur menu opacity dan fill seperti digunakan pada logo. 


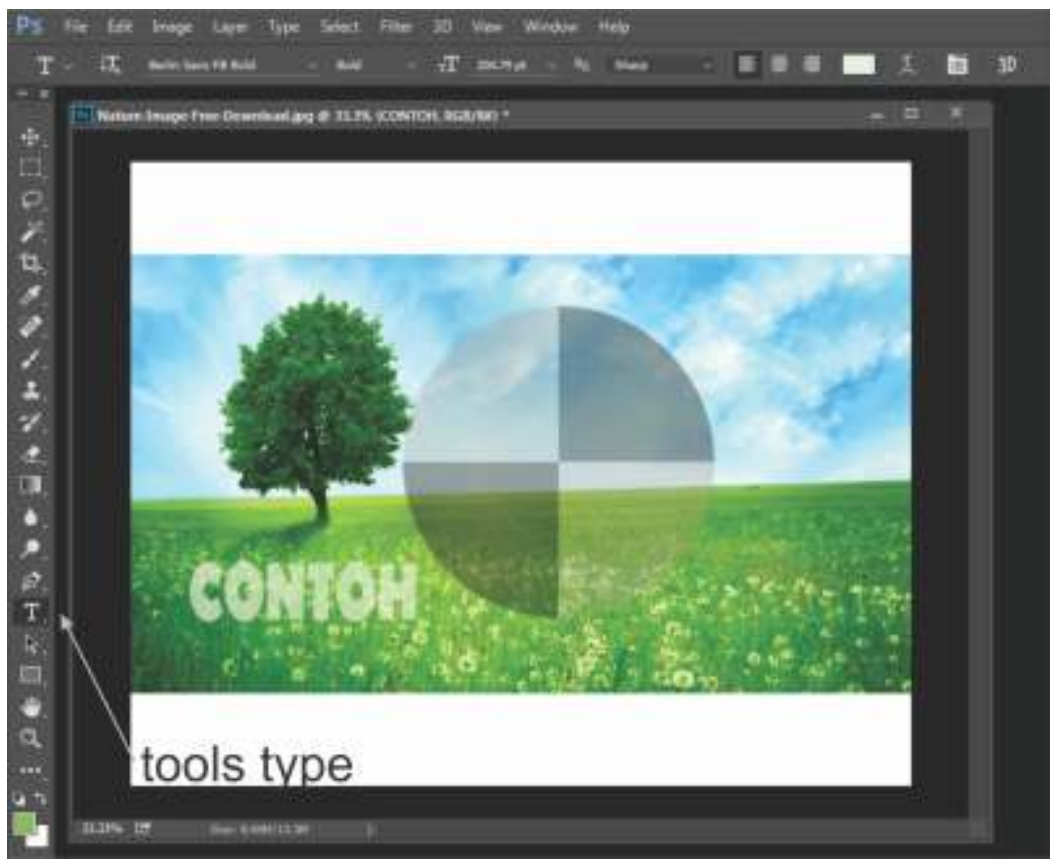

Gambar 7: Penerapan logo teks

f. Cara lainnya

Terdapat cara lain untuk memberi watermark baik logo maupun tulisan. Watermark dapat dibuat terlebih dahulu sebagai tipe brush. Gunakan Horizontal Type Tools pada file baru untuk membuat tulisan yang akan digunakan sebagai watermark, lalu olah tulisan tersebut sesuai kebutuhan (mengenai warna, ukuran, fill, dan opacity). Kemudian simpan dengan menu edit $>$ Define Brush Preset. Hal ini juga dapat diterapkan pada gambar logo.Tipe brush yang telah disimpan dapat diterapkan pada gambar target dengan brush tool.

g. Menyimpan gambar

Untuk menyimpan gambar yang telah diberi watermark, gunakan menu file $>$ safe, lalu pilih format gambar output yang 
diinginkan, dan tentukan lokasi simpan gambar baru pada komputer PC.

\section{Kesimpulan dan Saran}

Arsip adalah aset bernilai tinggi. Bahkan beberapa kalangan memandang bahwa arsip tak ternilai harganya. Selain pengamanan secara fisik dari kerusakan dan kehilangan, diperlukan juga pengamanan informasi agar tidak disalahgunakan. Pengguna arsip juga harus mencantumkan sumber arsip, sehingga arsip yang digandakan perlu diberi digital watermark.

Saat ini tersedia banyak

\section{DAFTAR PUSTAKA}

Machmoed Effendhie, dkk. 2010. Panduan Umum Digitalisasi Arsip, Yogyakarta: Arsip Universitas Gadjah Mada.

Peraturan Kepala Arsip Nasional Republik Indonesia Nomor 18 Tahun 2011 tentang Tata Cara aplikasi yang dapat digunakan untuk membubuhkan digital watermark. Aplikasi tersebut dapat dengan mudah dipelajari oleh arsiparis serta mudah untuk diaplikasikan dalam berbagai format arsip.

Penulis menyarankan agar pemberian digital watermark tetap disesuaikan dengan kaidah kearsipan. File arsip yang dibubuhi digital watermark hendaknya bukanlah file master, sehingga arsip aslinya tetaplah bersih dari apapun. Di samping itu, arsiparis hendaknya mengikuti kemajuan zaman dengan mempelajari aplikasi-aplikasi yang berhubungan dengan dunia

P e mbuat an Daftar, Pemberkasan dan Pelaporan, serta Penyerahan Arsip Terjaga.

Peraturan Kepala Arsip Nasional Republik Indonesia Nomor 30 Tahun 2011 tentang Pedoman Penggunaan Kertas untuk Arsip/Dokumen Permanen. 
Peraturan Kepala Arsip Nasional Republik Indonesia Nomor 28 Tahun 2014 tentang Penggunaan Digital Watermark pada Hasil Digitalisasi Arsip Vereenigde Oostindische Compagnie di Lingkungan Arsip Nasional Republik Indonesia.
Peraturan Kepala Arsip Nasional Republik Indonesia Nomor 2 Tahun 2014 tentang Pedoman Tata Naskah Dinas.

Undang-undang Nomor 43 tahun 2009 tentang Kerasipan.

https://id.wikipedia.org, diakses pada 17 Juni 2016. 